\title{
DEVELOPMENT OF SUBCONTRACTOR SELECTION MODELS USING FUZZY AND AHP METHODS IN THE APPAREL INDUSTRY SUPPLY CHAIN
}

\author{
Mourad Lahdhiri ${ }^{1,2 *}$, Amel Babay ${ }^{1}$, Mohamed Jmali ${ }^{1}$ \\ 1 Laboratory of Textile Engineering (LGtex), ISET Ksar Hellel, University of Monastir, Tunisia \\ 2 National Engineering School, University of Monastir, Monastir, Tunisia \\ *Corresponding author. E-mail: lahdhirimrad@yahoo.fr
}

\begin{abstract}
:
The subcontractor selection decision is inherently a multicriterion problem. It is a decision of strategic importance for companies. The nature of this decision is usually complex and unstructured. Management science techniques might be helpful tools for solving these kinds of decision-making problems. In this research, the fuzzy logic method and the analytic hierarchy process were applied for the selection of suitable subcontractors in an apparel supply chain.
\end{abstract}

In general, many factors, such as quality level, price offer, and delivery delay, were considered to determine the most suitable and reliable subcontractors that fit the company's strategy. This survey is carried out using the database of an apparel company manufacturing denim products.

\section{Keywords:}

Fuzzy model, analytic hierarchy process, apparel industry supply chain

\section{Introduction}

Nowadays subcontractors' categorization, selection, and performance evaluation are decisions of strategic importance for companies. Global competition, mass customization, high customer expectations, and harsh economic conditions are forcing companies to rely on external subcontractors to contribute a larger portion of parts, materials, and assemblies to finished products and to manage a growing number of processes and functions that were once controlled internally. The literature suggests that many studies are interested in this topic, one of them focused on supplier selection and evaluation using the multiple criteria decision-making model (MCDM) according to the concept TOPSIS based on the closeness coefficient, and as a result, this model gave the ranking of supplier and evaluation status of all suppliers [1]. Other research studies have used the fuzzy supplier selection algorithm, based on the ranking of the supplier, and found that the used model is an easy and realistic approach for supplier selection. It gives a concrete result by recording the purchasing experts' experiences and processes these with fuzzy logic arithmetic [2]. Maurizio et al. have used a fuzzy approach to determine the rank of the supplier, their attempts based on the fuzzy suitability index to determine the final ranking, and they approved that the fuzzy approach is able to deal with linguistic variables [3]. Felix et al. have developed their research according to the model fuzzy analytic hierarchy process (AHP), they combined the fuzzy method with the AHP method to clarify the fuzzy. As a result, the used model is proved to be simple, less time taking, and having a less computational expense. They found that the use of fuzzy AHP does not involve cumbersome mathematical operation and it is easy to handle the multiattribute decision-making problems like global supplier selection. They found that the combined fuzzy-AHP has the ability to capture the vagueness of human thinking style and effectively solve multiattribute decision-making problems [4]. In addition, Sharon et al. have described a decision model that incorporates a decision maker's subjective assessments and applies fuzzy arithmetic operators to manipulate and quantify these assessments. This model treated the subjectivity in linguistic terms [5]. Some other research studies have used an integrated approach of fuzzy multiattribute utility theory and multiobjective programming for rating and selecting the best suppliers and allocating the optimum order quantities; however, this study integrates fuzzy AHP, fuzzy TOPSIS, and fuzzy MOLP to solve the problem of supplier selection and order allocation. At first, they have used the fuzzy AHP to calculate the relative weights of supplier selection criteria; then, they have used the fuzzy TOPSIS for ranking of suppliers according to the selected criteria. Finally, the weights of the criteria and ranks of suppliers were incorporated into the MOLP model to determine the optimal order quantity from each supplier [6]. In the construction field, many research studies have used fuzzy logic for the selection and evaluation of subcontractors [7-9]. Kumar et al. have used a fuzzy goal programming approach for solving the vendor selection problem with multiple objectives, in which some of the parameters are fuzzy and they showed that this approach has the capability to handle realistic situations in a fuzzy environment and provides a better decision tool for the vendor selection decision in a supply chain [10]. Many researchers have used the fuzzy logic to predict the 
hydrophobic nature of knitted fabrics [11] and others have used the fuzzy logic for modeling the residual bagging behaviors of denim fabric [12]. Weber and Current have developed their research according to the model multiobjective programming [13]. In the work of Soukoup, he used the payoff matrix model that allows defining several scenarios of the future behavior of suppliers [14]. Ellram used a vendor profile analysis model to choose the best supplier [15]. Roodhooft and Konings have used a method based on the total cost to classify the supplier in descending order [16]. Hinkle et al. have used a cluster analysis model, which allows to group the suppliers according to the scores obtained [17]. In the field of supply chain management and, in particular, in the selection and evaluation of textile subcontractors, the majority of articles in the literature are concerned with the selection of the supplier. Given the importance of outsourcing in the textile sector, we have focused on this theme and tried to model the selection of subcontractors in a clothing supply chain for specific orders by using two methods, namely, the AHP and the fuzzy logic.

\section{Experimental section}

\subsection{Materials and methods}

\subsubsection{Data set used}

This work was carried out in a company specialized in manufacturing Denim products employing 350 persons with an annual production of 800,000 pieces. This company operates as an ordering party for several subcontractors and as a manufacturer of several items (pants, jackets, skirts, etc.) in small and medium orders for different international brands requiring high-quality level, good price, and short-time delivery.

In this study, a database composed of nine subcontractors of the company was used, and each subcontractor is characterized by four parameters, namely, daily production, late delivery, second choice ratio, and subcontractor price. The variation range of the dataset is indicated in Table 1.

As a sample, 30 production orders were used, and each production order is characterized by quantity, delivery delay, accepted defects ratio, and price per piece (Table 2).

\subsubsection{Fuzzy logic modeling}

The fuzzy logic is an extension of crisp logic, which was first proposed by Lotfi Zadeh [18]. In crisp logic, like binary logic, variables are true or false, 1 or 0 . In fuzzy logic, a fuzzy set contains elements with only partial membership ranging from 0 to 1 to define the uncertainty of classes that do not have clearly defined boundaries. For each input and output variable of a fuzzy inference system, the fuzzy sets are created by dividing the universe of discourse into several subregions, named in linguistic terms (high, medium, low, etc.).

\section{Fuzzy logic steps:}

\section{Step 1: Define the linguistic variables and terms}

Linguistic variables are the input or output variables of the system whose values are words or sentences from a natural language instead of numerical values.

\section{Step 2: Develop membership functions}

Membership functions are used in the fuzzification and defuzzification steps of a fuzzy logic system to map the nonfuzzy input values to fuzzy linguistic terms and vice versa. A membership function is used to quantify a linguistic term. There are different forms of membership functions such as triangular, trapezoidal, piecewise linear, Gaussian, or singleton [19] (Figure 19).

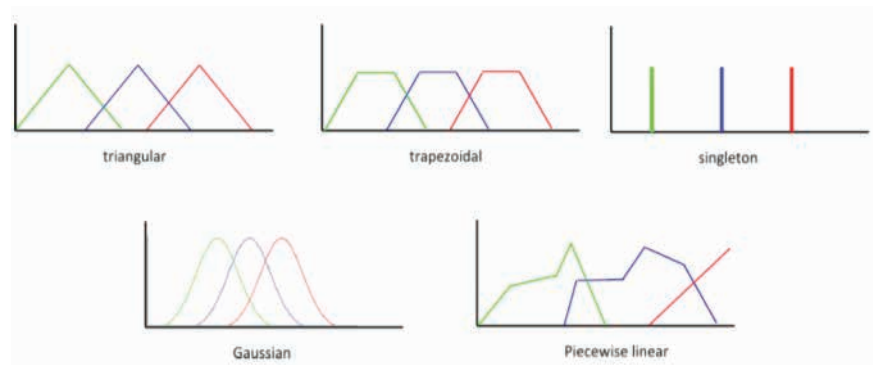

Figure 1: Different shapes of membership function graphs

Table 1: Subcontractors' parameters

\begin{tabular}{|c|c|c|c|c|}
\hline & Daily production (pieces/day) & Late delivery (days) & Second choice ratio (\%) & Price / piece (euro) \\
\hline Sub 1 & 650 & 7 & 0,66 & 0,7 \\
\hline Sub 2 & 700 & 6 & 0,8 & 1 \\
\hline Sub 3 & 600 & 4 & 0,4 & 0,6 \\
\hline Sub 4 & 600 & 0 & 0,3 & 0,5 \\
\hline Sub 5 & 700 & 8 & 0,7 & 1 \\
\hline Sub 6 & 500 & 4 & 0,71 & 0,5 \\
\hline Sub 7 & 700 & 2 & 0,51 & 0,7 \\
\hline Sub 8 & 650 & 5 & 0,5 & 1,2 \\
\hline Sub 9 & 800 & 10 & 0,9 & 0,9 \\
\hline
\end{tabular}


Table 2: Production order parameters

\begin{tabular}{|c|c|c|c|c|}
\hline $\begin{array}{c}\text { Number of } \\
\text { production order }\end{array}$ & Quantity (pieces) & Delivery delay (days) & $\begin{array}{c}\text { Accepted Defects ratio } \\
(\%)\end{array}$ & Price /piece (euro) \\
\hline 1 & 1200 & 14 & 4 & 0,7 \\
\hline 2 & 1415 & 14 & 2 & 0,4 \\
\hline 3 & 1001 & 14 & 4 & 0,7 \\
\hline 4 & 610 & 8 & 1 & 0,6 \\
\hline 5 & 240 & 8 & 1 & 1 \\
\hline 6 & 313 & 8 & 6 & 0,5 \\
\hline 7 & 178 & 23 & 6 & 0,5 \\
\hline 8 & 518 & 10 & 3 & 0,9 \\
\hline 9 & 805 & 17 & 2 & 0,6 \\
\hline 10 & 2329 & 17 & 3 & 1 \\
\hline 11 & 3003 & 14 & 2 & 0,6 \\
\hline 12 & 5000 & 10 & 2 & 0,9 \\
\hline 13 & 2560 & 17 & 1,5 & 1,1 \\
\hline 14 & 800 & 14 & 1 & 1 \\
\hline 15 & 300 & 7 & 4 & 0,5 \\
\hline 16 & 2329 & 17 & 2 & 0,7 \\
\hline 17 & 6780 & 11 & 5 & 0,45 \\
\hline 18 & 452 & 8 & 1 & 0,7 \\
\hline 19 & 4000 & 18 & 2 & 1 \\
\hline 20 & 586 & 14 & 3 & 1 \\
\hline 21 & 3000 & 15 & 1 & 0,8 \\
\hline 22 & 3350 & 12 & 2 & 0,5 \\
\hline 23 & 3200 & 11 & 1 & 0,5 \\
\hline 24 & 587 & 13 & 1 & 0,9 \\
\hline 25 & 782 & 1 & 1 & 0,5 \\
\hline 26 & 520 & 15 & 4 & 0,6 \\
\hline 27 & 250 & 0 & 2 & 0,5 \\
\hline 28 & 221 & 10 & 1 & 0,9 \\
\hline 29 & 224 & 3 & 2 & 0,7 \\
\hline 30 & 238 & 4 & 3 & 0,7 \\
\hline
\end{tabular}

\section{Step 3: Fuzzy inference}

The fuzzy rules deduce knowledge about the state of the system according to the linguistic qualifications provided in the fuzzification stage.

\section{Step 4: Defuzzification}

Fuzzy rule-based systems evaluate linguistic if-then rules using fuzzification, inference, and composition procedures. They produce fuzzy results that usually have to be converted into crisp output by defuzzification. 


\subsubsection{Analytic hierarchy process}

The process of hierarchical analysis is a structured technique for organizing and analyzing complex decisions, based on mathematics and psychology. It was developed by Thomas L. Saaty in 1970 [20]. It is used worldwide for a wide variety of decision-making processes whether government decisions, business, industry, health, shipbuilding, or education [21].

\subsection{AHP process}

The principal steps of the AHP algorithm are as follows:

- Structure a decision problem and criteria selection.

- Develop a pairwise comparison matrix for each criterion.

- Develop a pairwise comparison matrix for each alternative for each criterion.

- Calculate the coefficient consistency.

- Obtain an overall relative score for each alternative.

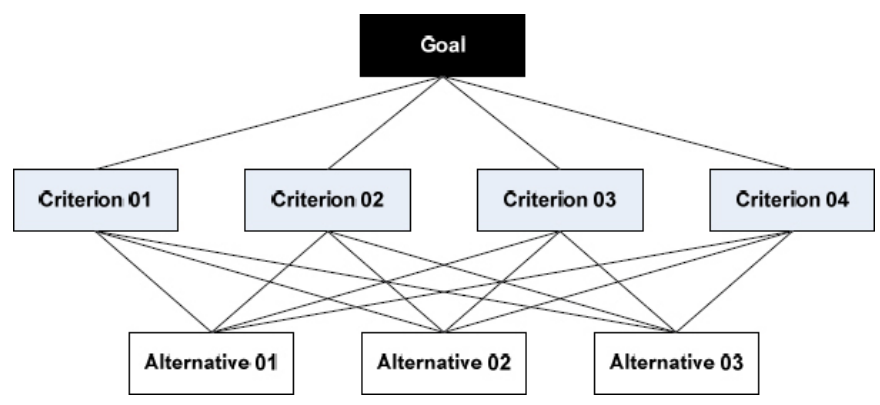

Figure 2: Analytic hierarchy process

Table 3: Saaty's 1-9 scale for pair-wise comparisons

\begin{tabular}{|c|c|}
\hline Numerical rate & Verbal judgment of preference \\
\hline 1 & Equal importance \\
\hline 3 & Weak importance of one over another \\
\hline 5 & Essential or strong importance \\
\hline 7 & Demonstrated importance \\
\hline 9 & Absolute importance \\
\hline $2,4,6,8$ & $\begin{array}{r}\text { Intermediate values between the two } \\
\text { adjacent judgment }\end{array}$ \\
\hline
\end{tabular}

Table 4: Pairwise comparison matrix of criterion

\begin{tabular}{|c|c|c|c|c|c|}
\hline Criteria & C1 & C2 & C3 & $\ldots$. & Cn \\
\hline $\mathrm{C} 1$ & 1 & $\mathrm{~W}_{1} / \mathrm{W}_{2}$ & $\mathrm{~W}_{1} / \mathrm{W}_{3}$ & $\ldots$ & $\mathrm{W}_{1} / \mathrm{W}_{\mathrm{n}}$ \\
\hline $\mathrm{C} 2$ & $\mathrm{~W}_{2} / \mathrm{W}_{1}$ & 1 & $\mathrm{~W}_{2} / \mathrm{W}_{3}$ & $\ldots$ & $\mathrm{W}_{2} / \mathrm{W}_{\mathrm{n}}$ \\
\hline $\mathrm{C} 3$ & $\mathrm{~W}_{3} / \mathrm{W}_{1}$ & $\mathrm{~W}_{3} / \mathrm{W}_{2}$ & 1 & $\ldots$ & $\mathrm{W}_{3} / \mathrm{W}_{\mathrm{n}}$ \\
\hline.. & $\ldots$ & $\ldots$ & $\ldots$ & 1 & $\ldots$ \\
\hline $\mathrm{Cn}$ & $\mathrm{W}_{\mathrm{n}} / \mathrm{W}_{1}$ & $\mathrm{~W}_{\mathrm{n}} / \mathrm{W}_{2}$ & $\mathrm{~W}_{\mathrm{n}} / \mathrm{W}_{3}$ & $\mathrm{~W}_{\mathrm{n}} / \mathrm{W}_{. .}$ & 1 \\
\hline
\end{tabular}

\subsubsection{Structuring a decision problem and the selection of criteria}

The first step in AHP is to develop a graphical representation of the problem in terms of the overall goal, the criteria, and the decision alternatives (Figure 2).

\subsubsection{Developing a pairwise comparison matrix for each criterion}

Step 1: Construct a pairwise comparison matrix $\left(n^{*} n\right)$ for criteria with respect to objective. The weights of the criteria should be calculated by using a pairwise comparison between criteria by applying Saaty's scales ranging from I to 9 (Table 3, 4).

Step 2: Normalize the resulting matrix: Sum the values in each column of the pairwise matrix.

Step 3: Divide each element in the matrix by its column total to generate a normalized pairwise matrix (Table 5).

$$
\mathrm{VS}=\left[\begin{array}{c}
V_{s 1} \\
V s 2 \\
\cdots \\
V s n
\end{array}\right]=\left[\begin{array}{c}
\frac{\sum_{j=1}^{n} \mathrm{x} 1 \mathrm{j}}{n} \\
\frac{\sum_{j=1}^{n} \mathrm{x} 2 \mathrm{j}}{n} \\
\cdots . \\
\frac{\sum_{j=1}^{n} \mathrm{X} \mathrm{nj}}{n}
\end{array}\right]
$$

Step 4: Calculate the row averages "Vs" of the normalized pairwise matrix, a weights vector is obtained:

\subsubsection{Developing a pairwise comparison matrix for each alternative for each criterion}

Step 1: Construct a pairwise comparison matrix $\left(n^{*} n\right)$ for criteria with respect to objective. The weights of the alternatives should be calculated by using a pairwise comparison between alternatives for each criterion by applying Saaty's scales ranging from I to 9 . The alternative in the row is being compared to the alternative in the column.

The next table shows the comparison matrix for each alternative for each criterion: for criteria C1 (Table 6).

Step 2: Normalizing the resulting matrix: Sum the values in each column of the pairwise matrix.

Table 5: Normalization Matrix

\begin{tabular}{|c|c|c|c|c|c|}
\hline Criteria & C1 & C2 & $\mathrm{C}_{3}$ & $\ldots$ & $\mathrm{Cn}$ \\
\hline $\mathrm{C} 1$ & $\mathrm{X}_{11}$ & $\mathrm{X}_{12}$ & $\mathrm{X}_{13}$ & $\ldots$ & $\mathrm{X}_{1 \mathrm{n}}$ \\
\hline $\mathrm{C} 2$ & $\mathrm{X}_{11}$ & $\mathrm{X}_{22}$ & $\mathrm{X}_{23}$ & $\ldots$ & $\mathrm{X}_{2 \mathrm{n}}$ \\
\hline $\mathrm{C} 3$ & $\mathrm{X}_{31}$ & $\mathrm{X}_{32}$ & $\mathrm{X}_{33}$ & $\ldots$ & $\mathrm{X}_{3 \mathrm{n}}$ \\
\hline.. & $\ldots$ & $\ldots$ & $\ldots$ & $\ldots$ & $\ldots$ \\
\hline $\mathrm{Cn}$ & $\mathrm{X}_{\mathrm{n} 1}$ & $\mathrm{X}_{\mathrm{n} 2}$ & $\mathrm{X}_{\mathrm{n} 3}$ & $\cdots$ & $\mathrm{X}_{\mathrm{nn}}$ \\
\hline
\end{tabular}


Table 6: Pairwise comparison matrix for each alternative for each criteria

\begin{tabular}{|c|c|c|c|c|c|}
\hline Alternative & A1 & A2 & A3 & $\ldots$ & An \\
\hline $\mathrm{A} 1$ & 1 & $\mathrm{~W}_{1} / \mathrm{W}_{2}$ & $\mathrm{~W}_{1} / \mathrm{W}_{3}$ & $\ldots$ & $\mathrm{W}_{1} / \mathrm{W}_{\mathrm{n}}$ \\
\hline $\mathrm{A} 2$ & $\mathrm{~W}_{2} / \mathrm{W}_{1}$ & 1 & $\mathrm{~W}_{2} / \mathrm{W}_{3}$ & $\ldots$ & $\mathrm{W}_{2} / \mathrm{W}_{\mathrm{n}}$ \\
\hline $\mathrm{A} 3$ & $\mathrm{~W}_{3} / \mathrm{W}_{1}$ & $\mathrm{~W}_{3} / \mathrm{W}_{2}$ & 1 & $\ldots$ & $\mathrm{W}_{3} / \mathrm{W}_{\mathrm{n}}$ \\
\hline.. & $\ldots$ & $\ldots$ & $\ldots$ & 1 & $\ldots$ \\
\hline $\mathrm{An}$ & $\mathrm{W}_{\mathrm{n}} / \mathrm{W}_{1}$ & $\mathrm{~W}_{\mathrm{n}} / \mathrm{W}_{2}$ & $\mathrm{~W}_{\mathrm{n}} / \mathrm{W}_{3}$ & $\mathrm{~W}_{\mathrm{n}} / \mathrm{W}_{2}$ & 1 \\
\hline
\end{tabular}

Table 7: Normalization Matrix

\begin{tabular}{|c|c|c|c|c|c|}
\hline Alternative & A1 & A2 & A3 & $\ldots$. & An \\
\hline A1 & $Y_{11}$ & $Y_{12}$ & $Y_{13}$ & $\ldots$ & $Y_{1 n}$ \\
\hline A2 & $Y_{11}$ & $Y_{22}$ & $Y_{23}$ & $\ldots$ & $Y_{2 n}$ \\
\hline A3 & $Y_{31}$ & $Y_{32}$ & $Y_{33}$ & $\ldots$ & $Y_{3 n}$ \\
\hline.. & $\ldots$ & $\ldots$ & $\ldots$ & $\ldots$ & $\ldots$ \\
\hline An & $Y_{n 1}$ & $Y_{n 2}$ & $Y_{n 3}$ & $\ldots$ & $Y_{n n}$ \\
\hline
\end{tabular}

Step 3: Divide each element in the matrix by its column total to generate a normalized pairwise matrix (Table 7).

Step 4: Calculate the row averages "Ts" of the normalized pairwise matrix, a weights vector is obtained

$$
\mathrm{Ts}=\left[\begin{array}{c}
T s 1 \\
T s 2 \\
\cdots \\
T s n
\end{array}\right]=\left[\begin{array}{c}
\frac{\sum_{j=1}^{n} \mathrm{Y} 1 \mathrm{j}}{n} \\
\frac{\sum_{j=1}^{n} \mathrm{Y} 2 \mathrm{j}}{n} \\
\cdots \cdot \cdot \\
\frac{\sum_{j=1}^{n} \mathrm{Ynj}}{n}
\end{array}\right]
$$

\subsubsection{Calculate the coefficient consistency}

To validate the results of the AHP, the consistency ratio $(C R)$ is calculated using the following equation:

$$
\mathrm{CR}=\frac{C I}{R I}:
$$

In which the consistency index $(\mathrm{Cl})$ is, in turn, measured through the following equation:

$$
\mathrm{Cl}=\frac{\lambda \max -\mathrm{n}}{\mathrm{n}-1} \text { : }
$$

With:

$\wedge$ max: maximum eigenvalue of the matrix

Table 8: Random Consistency Index (RI) $\mathrm{n}$ : order of the matrix.

The value of $\mathrm{RI}$ is related to the dimension of the matrix and will be extracted from the table (Table 8 ).

The CR has shown that a CR of 0.10 or less is acceptable to continue the AHP analysis. If the CR is greater than 0.10 , it is necessary to revise the judgments to locate the cause of the inconsistency and correct it.

\subsubsection{Obtaining an overall relative score for each alternative:}

Step 1: A matrix of solutions was created. For each alternative, the average value of each criterion for each alternative was taken (Table 9).

Table 9: Matrix of solution

\begin{tabular}{|c|c|c|c|c|c|c|}
\hline \multicolumn{7}{|c|}{ Criteria } \\
\hline \multirow{4}{*}{ alternatives } & & C1 & C2 & C3 & $\ldots$. & Cn \\
\cline { 2 - 7 } & $\mathrm{A} 1$ & $\mathrm{Ts}_{11}$ & $\mathrm{Ts}_{12}$ & $\mathrm{Ts}_{13}$ & $\ldots$ & $\mathrm{Ts}_{1 \mathrm{n}}$ \\
\cline { 2 - 7 } & $\mathrm{A} 2$ & $\mathrm{Ts}_{21}$ & $\mathrm{Ts}_{22}$ & $\mathrm{Ts}_{23}$ & $\ldots$ & $\mathrm{Ts}_{2 \mathrm{n}}$ \\
\cline { 2 - 7 } & $\mathrm{A} 3$ & $\mathrm{Ts}_{31}$ & $\mathrm{Ts}_{32}$ & $\mathrm{Ts}_{33}$ & $\ldots$ & $\mathrm{Ts}_{3 \mathrm{n}}$ \\
\cline { 2 - 7 } & $\cdots$ & $\ldots$ & $\ldots$ & $\ldots$ & $\ldots$ & $\ldots$ \\
\cline { 2 - 7 } & $\mathrm{An}$ & $\mathrm{Ts}_{\mathrm{n} 1}$ & $\mathrm{Ts}_{\mathrm{n} 2}$ & $\mathrm{Ts}_{\mathrm{n} 3}$ & $\ldots$ & $\mathrm{Ts}_{\mathrm{nn}}$ \\
\hline
\end{tabular}

Tsij: It represents the average vector for each alternative for each criterion.

Step 2: Determines the final ratings of the subcontractors: multiply the matrix of the solution and the average vector.

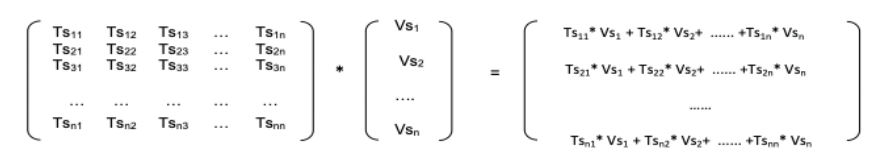

\subsubsection{Numerical example}

In this numerical example, we applied the fuzzy logic and the AHP model to choose the best subcontractors for a production order.

\section{Application of fuzzy logic method}

\section{Step 1: Definition of inputs and outputs}

The commands are taken as input and the subcontractors are taken as output into our system.

\begin{tabular}{|l|l|l|l|l|l|l|l|l|l|l|}
\hline $\mathrm{N}$ & 1 & 2 & 3 & 4 & 5 & 6 & 7 & 8 & 9 & 10 \\
\hline $\mathrm{RI}$ & 0 & 0.0 & 0.58 & 0.90 & 1.12 & 1.24 & 1.32 & 1.41 & 1.45 & 1.49 \\
\hline
\end{tabular}


The variables of an order (input):

- Quantity of the order

- Delivery delay

- Accepted defects ratio

- Production order price per piece

The variables of a subcontractor (Output):

- Daily production capacity

- Late delivery

- Second choice ratio

- Subcontractor price per piece

Fuzzy sets for each input and output:

Three classes are chosen for each input and output variables, which are as follows:

- Low

- Medium

- High

\section{Step 2: Develop membership functions}

Before creating the membership function, the classes of each input and output variable were determined in collaboration with an expert in industrial planning as already indicated in the tables (Table 10, 11, Figure 3,4).

Table 10: Classification of input variables

\begin{tabular}{|c|c|c|c|}
\hline & \multicolumn{3}{|c|}{ Classification } \\
\hline & Low & Medium & High \\
\hline $\begin{array}{l}\text { quantity of } \\
\text { production order } \\
\text { (pieces) }\end{array}$ & $0-450$ & $450-2000$ & $\begin{array}{l}2000- \\
10000\end{array}$ \\
\hline $\begin{array}{l}\text { Delivery delay } \\
\text { (days) }\end{array}$ & $0-12$ & $12-26$ & $26-28$ \\
\hline $\begin{array}{l}\text { Accepted quality } \\
\text { level (\%) }\end{array}$ & $0-2,5$ & $2,5-4,5$ & $4,5-6$ \\
\hline $\begin{array}{l}\text { Production order } \\
\text { price / piece } \\
\text { (Euro) }\end{array}$ & $0-0,6$ & $0,6-1,1$ & $1,1-2$ \\
\hline
\end{tabular}

\section{Step 3: Fuzzy inference:}

In this step, we have entered the fuzzy rules that connect the subsets of inputs and outputs. This step is to determine the relationships between the input set and the outputs. Table 12 shows the relationships between inputs and outputs $(\mathrm{H}$ : high; M: medium; L: low) (Table 12).

The operators used in this case are the "Mamdani"-type operators. So, the inference engine will be like this (Figure 5).

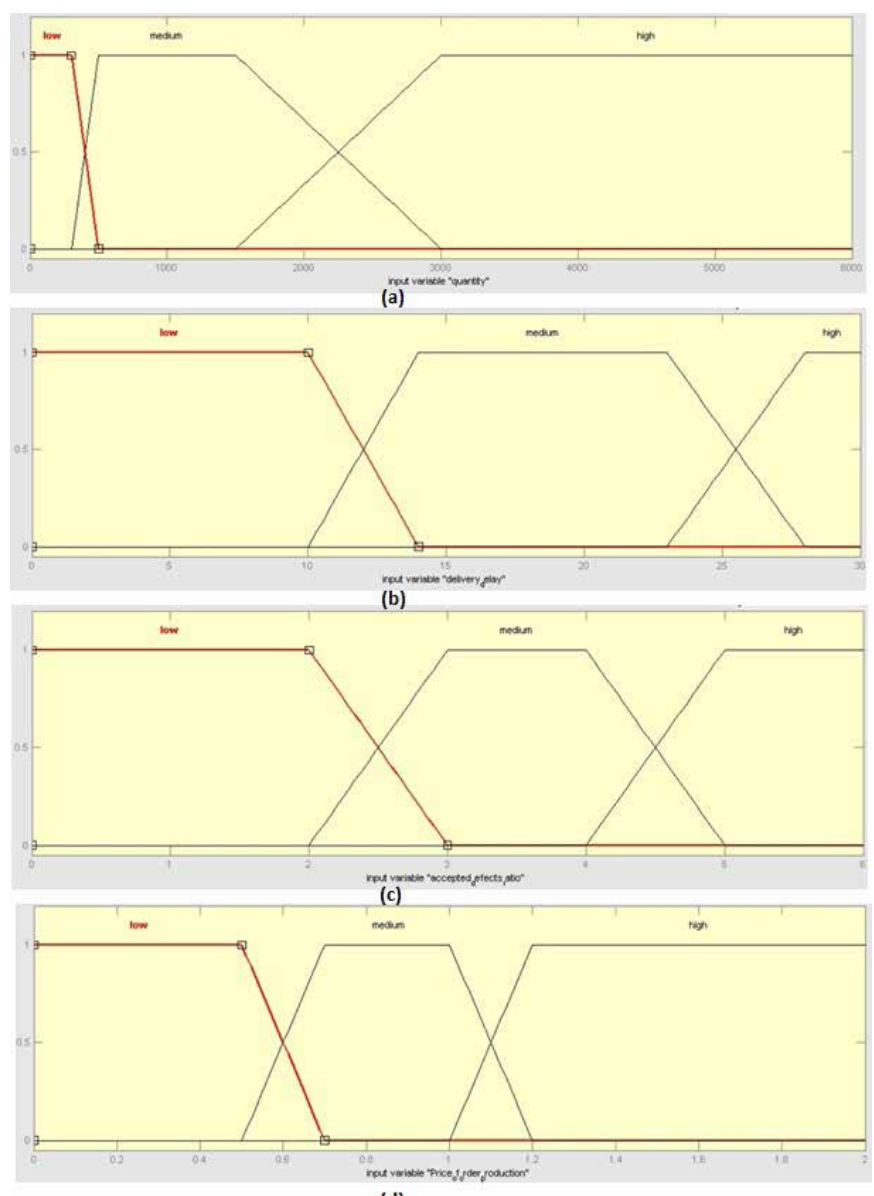

(d)

Figure 3: The membership function for the input variables

Table 11: Classification of output variables

\begin{tabular}{|c|c|c|c|}
\hline & \multicolumn{3}{|c|}{ Classification } \\
\hline & Low & Medium & High \\
\hline $\begin{array}{l}\text { Daily production } \\
\text { (pieces) }\end{array}$ & $0-400$ & $400-650$ & $650-1000$ \\
\hline $\begin{array}{l}\text { Late delivery } \\
\text { (days) }\end{array}$ & $0-2$ & $2-6$ & $6-10$ \\
\hline $\begin{array}{l}\text { Second choice } \\
\text { ratio (\%) }\end{array}$ & $0-0,3$ & $0,3-0,65$ & $0,65-2$ \\
\hline $\begin{array}{c}\text { subcontractor } \\
\text { price / piece (euro) }\end{array}$ & $0-0,6$ & $0,6-1,1$ & $1,1-2$ \\
\hline
\end{tabular}




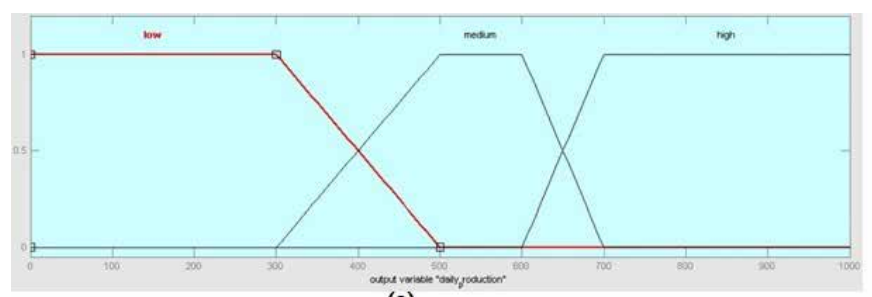

(a)

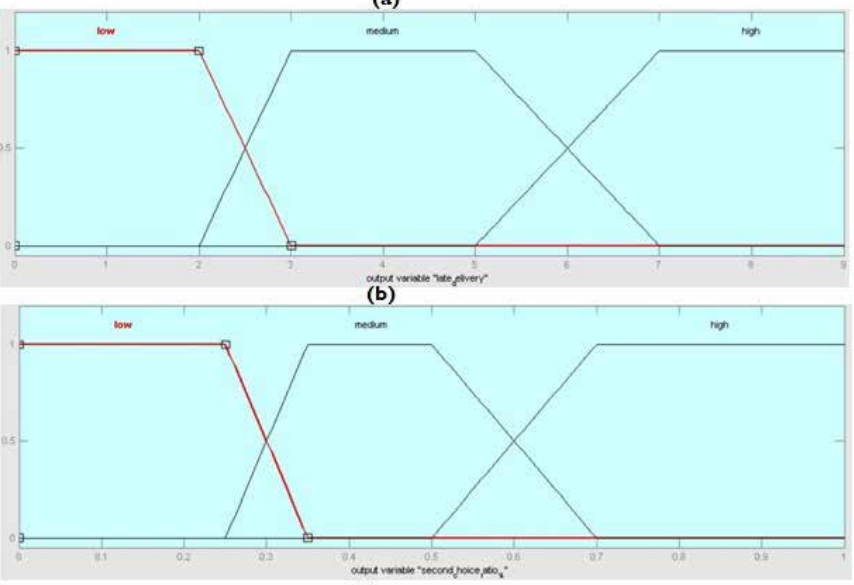

(c)

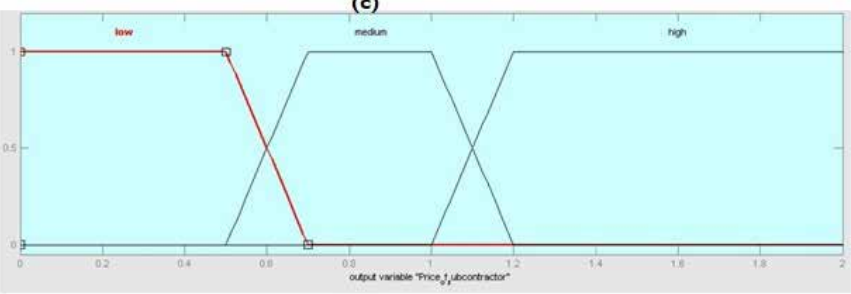

(d)

Figure 4: The membership function for the output variables

\section{Step 4: Defuzzification}

In this step, the center of gravity method was used for defuzzification. Figure 6 shows the rules window under Matlab where we can choose our inputs for the system to predict results (Figure 6).

\section{Step 5: Model validation}

To evaluate the fuzzy system, a dataset composed of 10 samples was used. Each input data is characterized by the order number, quantity, delivery delay, accepted defects ratio, and price per piece. Then, these data were tested in a real case. It should be noted that these orders, which are already assigned to well-chosen subcontractors, are selected from those which have been successfully performed. The selected subcontractors are called desired results, as shown in Figure 7. Afterward, these data were tested in our fuzzy logic system. The obtained results are mentioned in the same figure as the calculated results. Since each subcontractor is defined, the fuzzy model will calculate and deduct four outputs (daily production, the late delivery, the second choice ratio, and subcontractor price). To test the reliability of our system, the correlation between the desired and the calculated values for the three output parameters is established as plotted in Figure 7.

According to Figure 7, it is shown that we have obtained good correlation results. The correlation coefficients are $0.807,0.702$, 0.823 , and 0.871 for, respectively, the daily production, the late delivery, the second choice defects ratio, and the subcontractor

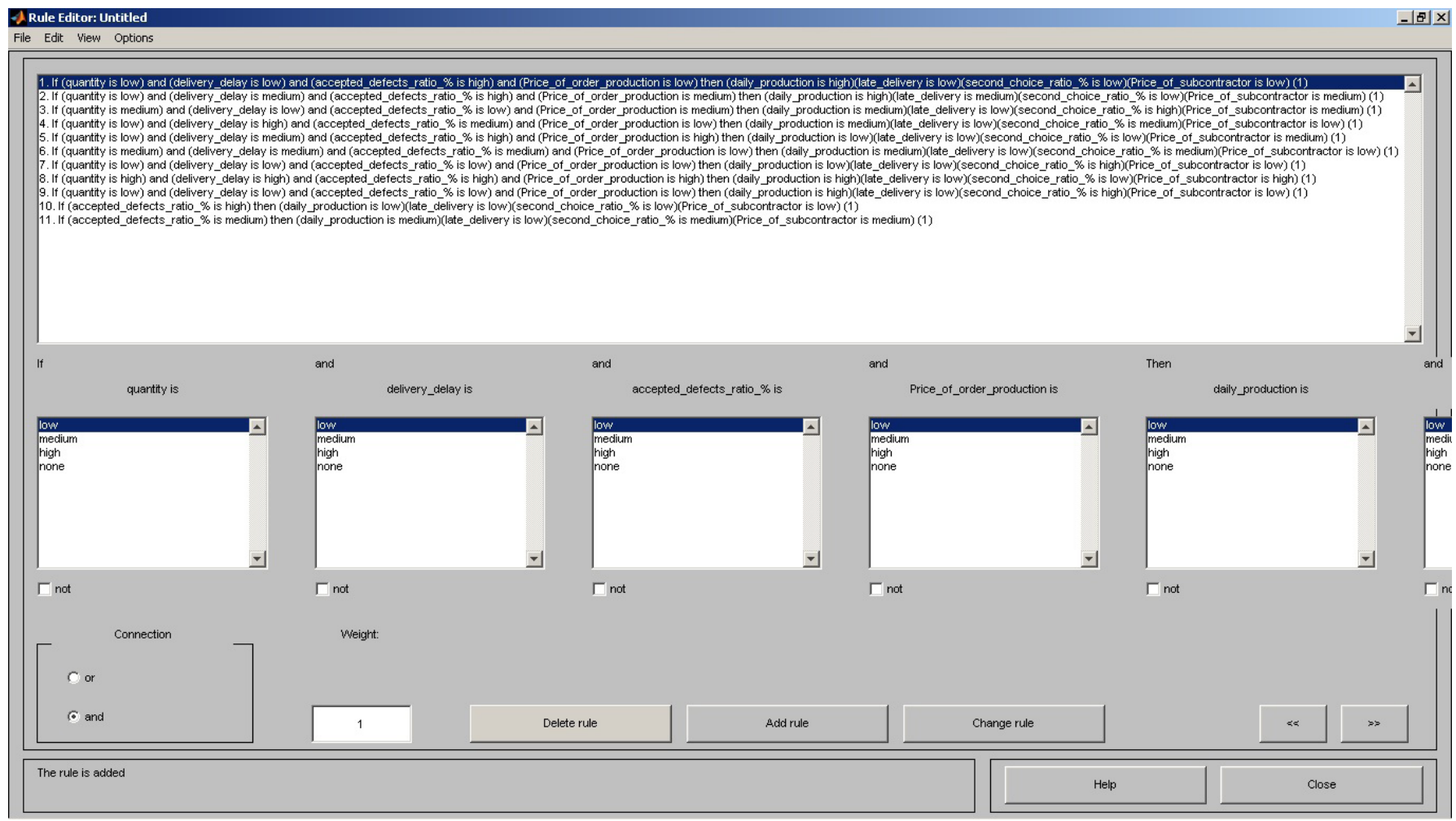

Figure 5: Table of inference rules under Matlab 
Table 12: List of Rules

\begin{tabular}{|c|c|c|c|c|c|c|c|}
\hline $\begin{array}{c}\text { Accepted } \\
\text { defects } \\
\text { ratio (\%) }\end{array}$ & $\begin{array}{c}\text { Quantity of } \\
\text { production } \\
\text { order } \\
\text { (pieces) }\end{array}$ & $\begin{array}{c}\text { Delivery } \\
\text { delay } \\
\text { (days) }\end{array}$ & $\begin{array}{c}\text { Production order } \\
\text { price / piece } \\
\text { (euro) }\end{array}$ & $\begin{array}{c}\text { Second } \\
\text { choice } \\
\text { ratio } \\
\text { (\%) }\end{array}$ & $\begin{array}{c}\text { Daily } \\
\text { production } \\
\text { (pieces/day) }\end{array}$ & $\begin{array}{c}\text { Late } \\
\text { delivery } \\
\text { (days) }\end{array}$ & $\begin{array}{c}\text { Subcontractor } \\
\text { price / piece } \\
\text { (euro) }\end{array}$ \\
\hline $\mathrm{H}$ & $\mathrm{L}$ & $\mathrm{L}$ & $\mathrm{L}$ & $\mathrm{L}$ & $\mathrm{H}$ & $\mathrm{L}$ & $\mathrm{L}$ \\
\hline $\mathrm{H}$ & $\mathrm{L}$ & $\mathrm{M}$ & $\mathrm{M}$ & $\mathrm{L}$ & $\mathrm{H}$ & $\mathrm{M}$ & $\mathrm{M}$ \\
\hline $\mathrm{L}$ & $\mathrm{M}$ & $\mathrm{L}$ & $\mathrm{M}$ & $\mathrm{H}$ & $\mathrm{M}$ & $\mathrm{L}$ & $\mathrm{M}$ \\
\hline $\mathrm{M}$ & $\mathrm{L}$ & $\mathrm{H}$ & $\mathrm{L}$ & $\mathrm{M}$ & $\mathrm{M}$ & $\mathrm{L}$ & $\mathrm{L}$ \\
\hline $\mathrm{H}$ & $\mathrm{L}$ & $\mathrm{M}$ & $\mathrm{H}$ & $\mathrm{L}$ & $\mathrm{L}$ & $\mathrm{L}$ & $\mathrm{M}$ \\
\hline $\mathrm{M}$ & $\mathrm{M}$ & $\mathrm{M}$ & $\mathrm{L}$ & $\mathrm{M}$ & $\mathrm{M}$ & $\mathrm{L}$ & $\mathrm{L}$ \\
\hline $\mathrm{L}$ & $\mathrm{L}$ & $\mathrm{L}$ & $\mathrm{L}$ & $\mathrm{H}$ & $\mathrm{L}$ & $\mathrm{L}$ & $\mathrm{L}$ \\
\hline $\mathrm{H}$ & $\mathrm{H}$ & $\mathrm{H}$ & $\mathrm{H}$ & $\mathrm{L}$ & $\mathrm{H}$ & $\mathrm{L}$ & $\mathrm{H}$ \\
\hline $\mathrm{L}$ & $\mathrm{L}$ & $\mathrm{L}$ & $\mathrm{L}$ & $\mathrm{H}$ & $\mathrm{H}$ & $\mathrm{L}$ & $\mathrm{L}$ \\
\hline $\mathrm{H}$ & - & - & - & $\mathrm{L}$ & $\mathrm{L}$ & $\mathrm{L}$ & $\mathrm{L}$ \\
\hline $\mathrm{M}$ & - & - & - & $\mathrm{M}$ & $\mathrm{M}$ & $\mathrm{L}$ & $\mathrm{M}$ \\
\hline
\end{tabular}

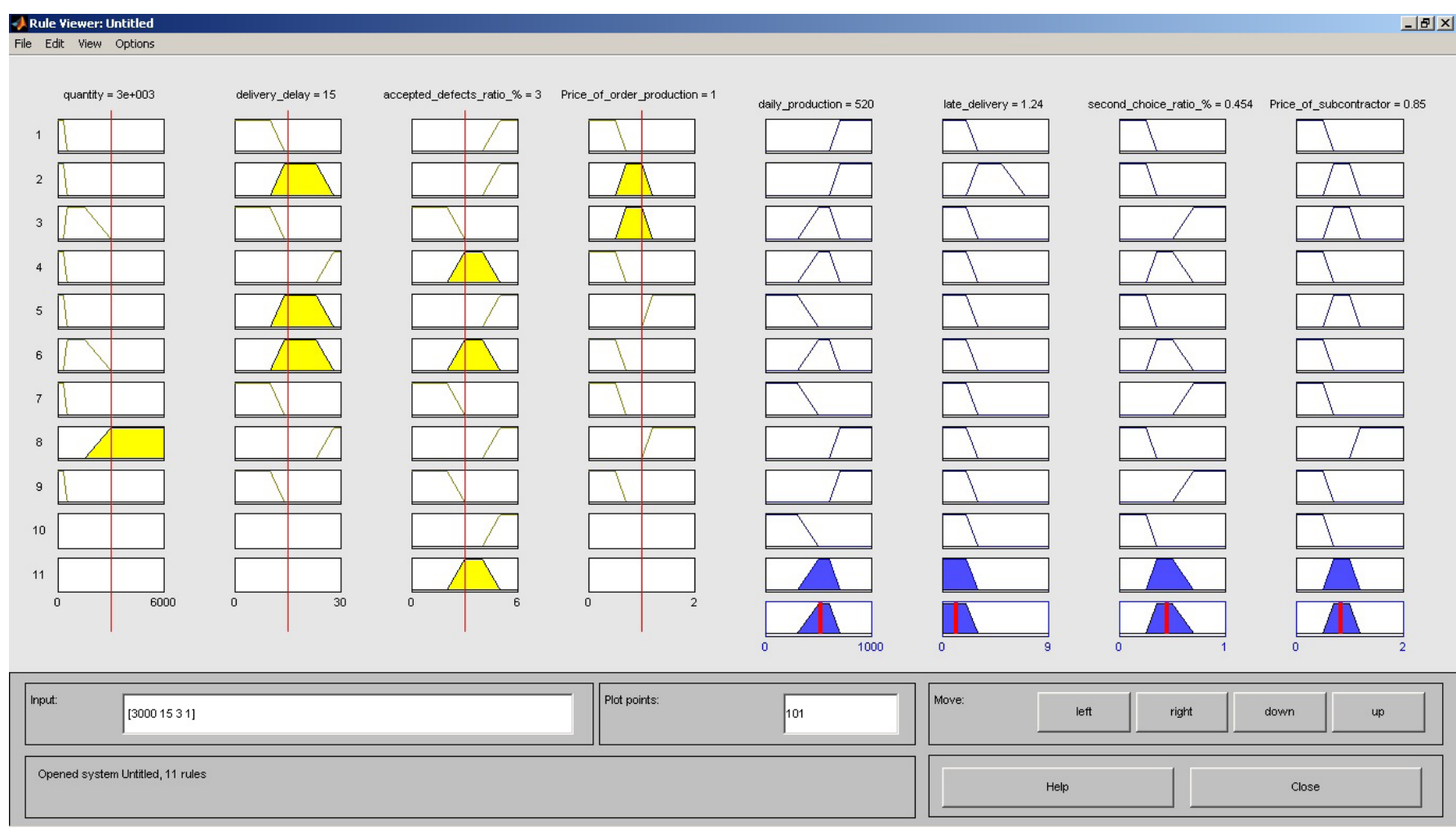

Figure 6: The defuzzification steps under Matlab.

price. Our model was tested for a production order with the values of the following parameters summarized in Table 13.

The parameters of the subcontractors are used in Table 14.

The result was indicated in Table 15.

\section{Application of AHP method}

Step 1: Define the criteria for subcontractor selection for a production order with the following parameters (Table 16).
Step 2: The AHP process is determined in Figure 8.

Step 3: The criteria matrix of decisions based on Saaty's scale is given as follows (Table 17).

Step 4: Normalize the resulting matrix (Table 18).

Step 5: Develop a pairwise comparison matrix for each subcontractor for the criterion: quality (Table 19).

Step 6: Normalize the resulting matrix (Table 20). 
Table 13: Production order parameters

\begin{tabular}{|c|c|}
\hline Quantity (pieces) & 1001 \\
\hline Delivery delay (days) & 14 \\
\hline Accepted quality level (\%) & 4 \\
\hline Price / piece (euro) & 0,7 \\
\hline
\end{tabular}

Table 14: Subcontractors parameters

\begin{tabular}{|c|c|c|c|c|}
\hline & $\begin{array}{c}\text { Daily } \\
\text { production } \\
\text { (pieces/day) }\end{array}$ & $\begin{array}{c}\text { Late } \\
\text { delievery } \\
\text { (days) }\end{array}$ & $\begin{array}{c}\text { Second } \\
\text { choice } \\
\text { ratio (\%) }\end{array}$ & $\begin{array}{c}\text { Price / } \\
\text { piece } \\
\text { (euro) }\end{array}$ \\
\hline Sub 1 & 650 & 7 & 0,66 & 0,7 \\
\hline Sub 2 & 700 & 6 & 0,8 & 1 \\
\hline Sub 3 & 600 & 4 & 0,4 & 0,6 \\
\hline Sub 4 & 640 & 0 & 0,3 & 0,5 \\
\hline
\end{tabular}

Table 15: Subcontractors rank

\begin{tabular}{|c|c|}
\hline Subcontractors & $\begin{array}{c}\text { Subcontractors rank for } \\
\text { the production order }\end{array}$ \\
\hline Sub 4 & $\mathbf{1}$ \\
\hline Sub 2 & $\mathbf{2}$ \\
\hline Sub 3 & $\mathbf{3}$ \\
\hline Sub 1 & $\mathbf{4}$ \\
\hline
\end{tabular}

Table 16: Production order parameters

\begin{tabular}{|c|c|}
\hline Quantity (pieces) & 1001 \\
\hline Delivery delay (days) & 14 \\
\hline Accepted quality level (\%) & 4 \\
\hline Price / piece (euro) & 0,7 \\
\hline
\end{tabular}

Step 7: To validate the results, the CR was calculated as follows (Table 21).

The coefficient consistency is equal to 0.05 , so the results are considered good.

Step 8: Develop a pairwise comparison matrix for each subcontractor for the criterion: capacity (Table 22).

Step 9: Normalize the resulting matrix (Table 23).

Step 10: To validate the results, the CR was calculated as follows (Table 24).

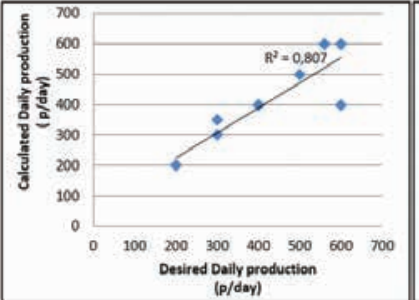

(a)

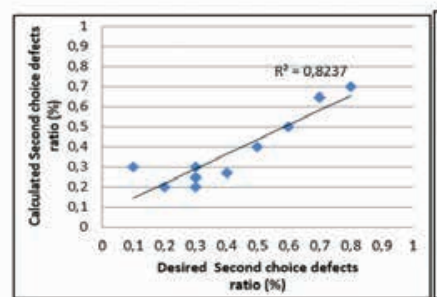

(c)

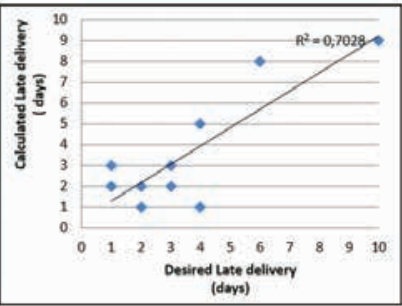

(b)

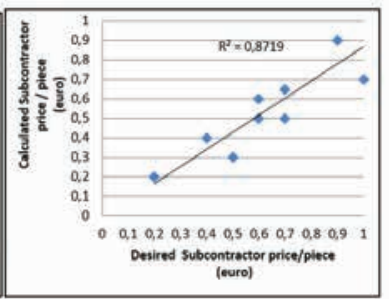

(d)
Figure 7: The correlation between the desired and the calculated values: (a) the daily production, (b) the late delivery, (c) second choice defects ratio and subcontractor price per piece

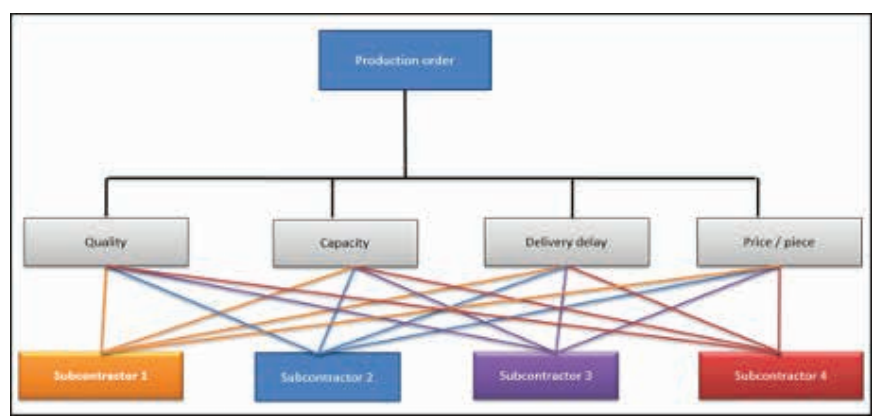

Figure 8: AHP process of production order

Acceptable results are obtained since the coefficient consistency is equal to 0.1 .

Step 11: Develop a pairwise comparison matrix for each subcontractor for the criterion: delivery delay (Table 25).

Step 12: Normalize the resulting matrix (Table 26).

Step 13: To validate the results, the CR was calculated as follows (Table 27).

Acceptable results are obtained since the coefficient consistency is equal to 0.08 less than 0.1 .

Step 14: Develop a pairwise comparison matrix for each subcontractor for the criterion: price/piece (Table 28).

Step 15: Normalize the resulting matrix (Table 29).

Step 16: To validate the results, the CR was calculated as follows (Table 30 ).

Acceptable results are obtained since the coefficient consistency is equal to 0.04 less than 0.1 . 
Table 17: Pairwise comparison matrix of criterion

\begin{tabular}{|c|c|c|c|c|}
\hline Criteria & Quality & Capacity & Delivery delay & Price/ piece \\
\hline Quality & 1 & $1 / 5$ & $1 / 7$ & 7 \\
\hline Capacity & 5 & 1 & 1 & 7 \\
\hline Delivery delay & 7 & $1 / 7$ & $1 / 3$ & 1 \\
\hline Price / piece & $1 / 3$ & $1 / 7$ & 7 \\
\hline
\end{tabular}

Table 18: Normalization matrix

\begin{tabular}{|c|c|c|c|c|}
\hline Criteria & Quality & Capacity & Delivery delay & Price / piece \\
\hline Quality & 0,08 & 0,13 & 0,02 & 0,21 \\
\hline Capacity & 0,38 & 0,67 & 0,83 & 0,50 \\
\hline Delivery delay & 0,53 & 0,10 & 0,12 & 0,21 \\
\hline Price / piece & 0,03 & 0,10 & 0,04 & 0,07 \\
\hline
\end{tabular}

Table 19: Pairwise comparison matrix for each subcontractor for the criterion: quality

\begin{tabular}{|c|c|c|c|}
\hline alternatives & Sub 1 & Sub 2 & Sub 3 \\
\hline Sub 1 & 1 & $1 / 3$ & $1 / 5$ \\
\hline Sub 2 & 3 & $1 / 7$ & $1 / 3$ \\
\hline Sub 3 & 5 & 3 & $1 / 2$ \\
\hline Sub 4 & 7 & 2 & 2 \\
\hline
\end{tabular}

Table 20: Normalization matrix

\begin{tabular}{|c|c|c|c|c|c|}
\hline alternatives & Sub 1 & Sub 2 & Sub 3 & Sub 4 & Ts \\
\hline Sub 1 & 0,06 & 0,02 & 0,06 & 0,07 & 0,05 \\
\hline Sub 2 & 0,19 & 0,16 & 0,09 & 0,23 & 0,17 \\
\hline Sub 3 & 0,31 & 0,47 & 0,28 & 0,23 & 0,33 \\
\hline Sub 4 & 0,44 & 0,32 & 0,57 & 0,47 & 0,45 \\
\hline
\end{tabular}

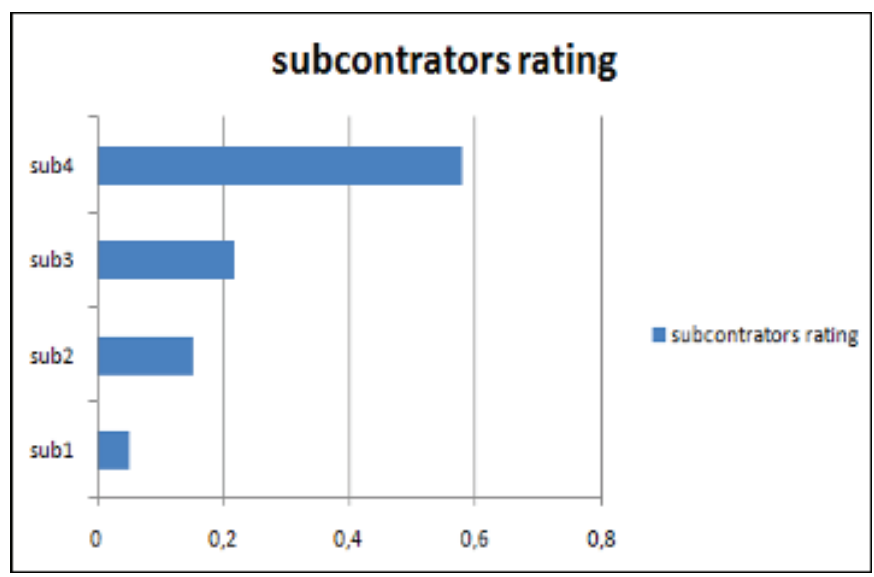

Figure 9: The ranking of subcontractors
Table 21: Consistency ratio

\begin{tabular}{|c|c|}
\hline & $\mathbf{4 , 1 4}$ \\
\hline $\mathrm{Cl}$ & 0,05 \\
\hline $\mathrm{RI}$ & 0,90 \\
\hline $\mathrm{CR}$ & 0,05 \\
\hline
\end{tabular}

Step 17: Obtain an overall relative score for each alternative by creating a matrix of solutions. For each subcontractor, the average value of each criterion for each subcontractor was taken (Table 31).

Step 15: The final ratings of the suppliers were determined by multiplying the matrix of the solution and the average vector (Vs) (Figure 9). 
Table 22: Pairwise comparison matrix for each subcontractor for the criterion: capacity

\begin{tabular}{|c|c|c|c|c|}
\hline alternatives & Sub 1 & Sub 2 & Sub 3 & Sub 4 \\
\hline Sub 1 & 1 & $1 / 3$ & $1 / 5$ & $1 / 9$ \\
\hline Sub 2 & 3 & 1 & $1 / 2$ & $1 / 7$ \\
\hline Sub 3 & 5 & 2 & 7 & 1 \\
\hline Sub 4 & 9 & 3 & & $1 / 3$ \\
\hline
\end{tabular}

Table 23: Normalization matrix

\begin{tabular}{|c|c|c|c|c|c|}
\hline alternatives & Sub 1 & Sub 2 & Sub 3 & Sub 4 & Ts \\
\hline Sub 1 & 0,06 & 0,05 & 0,02 & 0,05 \\
\hline Sub 2 & 0,17 & 0,16 & 0,06 & 0,21 & 0,15 \\
\hline Sub 3 & 0,28 & 0,32 & 0,11 & 0,09 & 0,20 \\
\hline Sub 4 & 0,50 & 0,47 & 0,80 & 0,63 & 0,60 \\
\hline
\end{tabular}

Table 24: Consistency ratio

\begin{tabular}{|c|c|}
\hline & $\mathbf{4 , 3 4}$ \\
\hline $\mathrm{Cl}$ & 0,11 \\
\hline $\mathrm{RI}$ & 0,90 \\
\hline $\mathrm{CR}$ & 0,10 \\
\hline
\end{tabular}

Table 25: Pairwise comparison matrix for each subcontractor for the criterion: delivery delay

\begin{tabular}{|c|c|c|c|c|}
\hline alternatives & Sub 1 & Sub 2 & Sub 3 & Sub 4 \\
\hline Sub 1 & 1 & $1 / 3$ & $1 / 5$ & $1 / 7$ \\
\hline Sub 2 & 3 & 1 & $1 / 2$ & $1 / 3$ \\
\hline Sub 3 & 5 & 2 & 1 & $1 / 5$ \\
\hline Sub 4 & 7 & 3 & 5 & 1 \\
\hline
\end{tabular}

From this figure, subcontractor number 4 represents the best choice to treat the production order.

\section{Results and discussion}

To evaluate the performance of the method AHP and fuzzy logic in predicting the best choice of the subcontractor, a dataset composed of 30 samples was used. Each input data is characterized by the order number, quantity, delivery delay, accepted defects ratio, and production order price per piece. Then, these data were tested in a real case. It should be noted that these orders, which are given to well-defined subcontractors, are selected from those which have been successful in the choice that was made.

Table 32 presents the rank of the solution adopted by the company in the list of solutions determined by both the AHP method and the fuzzy logic.

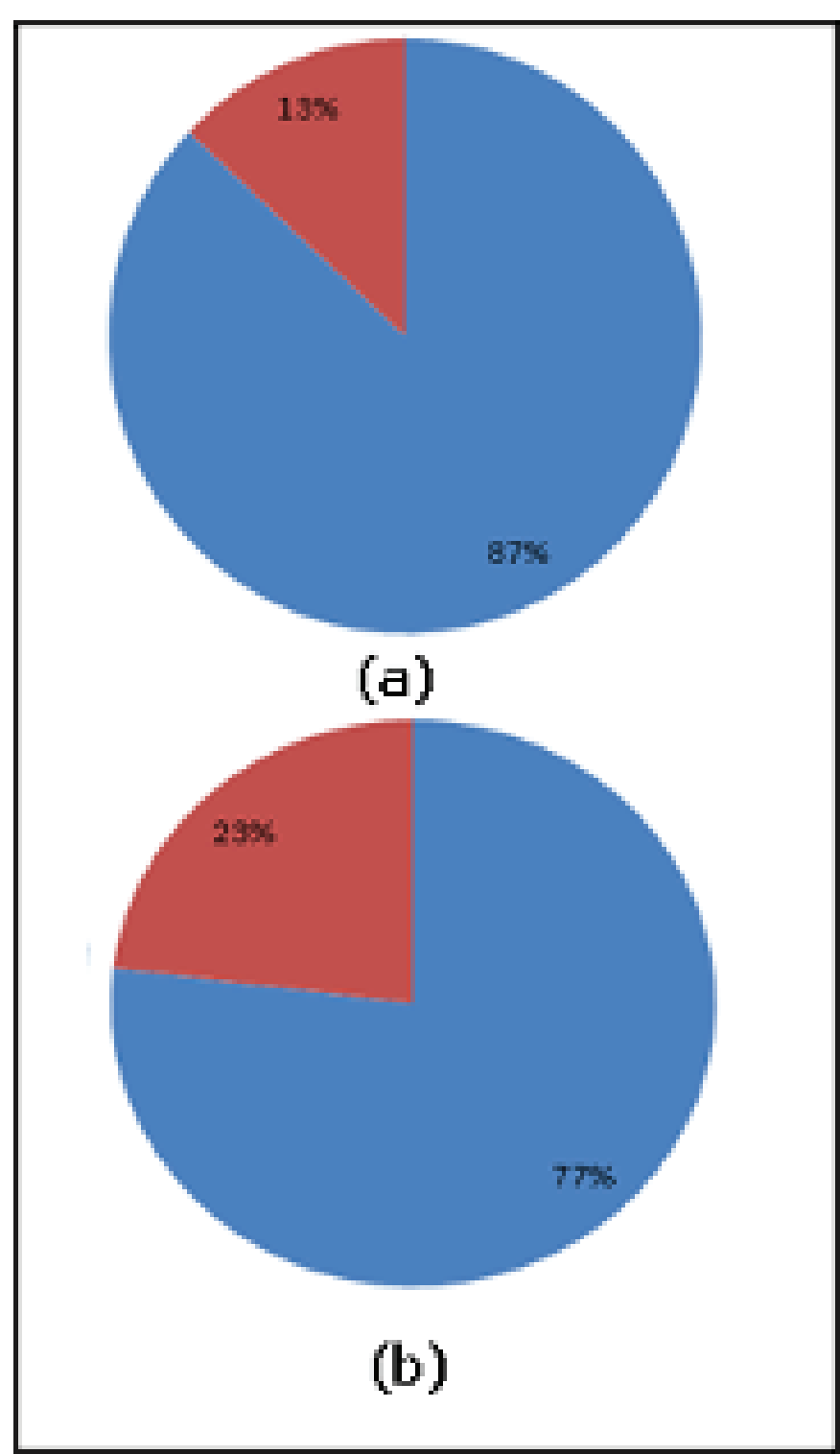

Figure 10: Percentage of coincidence for the AHP method and the fuzzy logic with the choice of the company 
Table 26: Normalization matrix

\begin{tabular}{|c|c|c|c|c|c|}
\hline alternatives & Sub 1 & Sub 2 & Sub 3 & Sub 4 & Ts \\
\hline Sub 1 & 0,06 & 0,05 & 0,03 & 0,09 & 0,06 \\
\hline Sub 2 & 0,19 & 0,16 & 0,07 & 0,20 & 0,15 \\
\hline Sub 3 & 0,31 & 0,32 & 0,15 & 0,12 & 0,22 \\
\hline Sub 4 & 0,44 & 0,47 & 0,75 & 0,60 & 0,56 \\
\hline
\end{tabular}

Table 27: Consistency ratio

\begin{tabular}{|c|c|}
\hline & $\mathbf{4 , 2 1}$ \\
\hline $\mathrm{Cl}$ & 0,07 \\
\hline $\mathrm{RI}$ & 0,90 \\
\hline $\mathrm{CR}$ & 0,08 \\
\hline
\end{tabular}

Table 28: Pairwise comparison matrix for each subcontractor for the criterion: Price/ piece

\begin{tabular}{|c|c|c|c|c|}
\hline alternatives & Sub 1 & Sub 2 & Sub 3 & Sub 4 \\
\hline Sub 1 & 1 & 3 & 4 & 2 \\
\hline Sub 2 & $1 / 3$ & 1 & 1 & $1 / 5$ \\
\hline Sub 3 & $1 / 4$ & $1 / 2$ & 8 & $1 / 8$ \\
\hline Sub 4 & 5 & 7 & 1 \\
\hline
\end{tabular}

Table 29: Normalization matrix

\begin{tabular}{|c|c|c|c|c|c|}
\hline alternatives & Sub 1 & Sub 2 & Sub 3 & Sub 4 & Ts \\
\hline Sub 1 & 0,15 & 0,26 & 0,27 & 0,14 & 0,20 \\
\hline Sub 2 & 0,05 & 0,09 & 0,13 & 0,10 & 0,09 \\
\hline Sub 3 & 0,04 & 0,04 & 0,07 & 0,09 & 0,06 \\
\hline Sub 4 & 0,76 & 0,61 & 0,53 & 0,68 & 0,65 \\
\hline
\end{tabular}

Table 30: Consistency ratio

\begin{tabular}{|c|c|}
\hline & $\mathbf{4 , 1 2}$ \\
\hline $\mathrm{Cl}$ & 0,07 \\
\hline $\mathrm{RI}$ & 0,90 \\
\hline $\mathrm{CR}$ & 0,04 \\
\hline
\end{tabular}

Table 31: Matrix of solution

\begin{tabular}{|c|c|c|c|c|c|}
\hline \multicolumn{9}{|c|}{ Criteria } \\
\hline \multirow{3}{*}{ alternatives } & Quality & Capacity & Delivery delay & Price / piece \\
\cline { 2 - 7 } & Sub 1 & 0,05 & 0,05 & 0,06 & 0,02 \\
\cline { 2 - 7 } & Sub 2 & 0,17 & 0,15 & 0,15 & 0,09 \\
\cline { 2 - 7 } & Sub 3 & 0,33 & 0,2 & 0,22 & 0,06 \\
\cline { 2 - 7 } & Sub 4 & 0,45 & 0,6 & 0,56 & 0,65 \\
\hline
\end{tabular}

From Figure 10, we can conclude that the found results are very acceptable. The percentage of a coincidence for the AHP method with the choice of the company is equal to $87 \%$, as for the fuzzy logic method, this percentage is about $77 \%$. Based on these results, we can conclude that both methods are efficient, but, in our case, the AHP method was more efficient than the fuzzy logic method. Figures 11 and 12 give more details. 


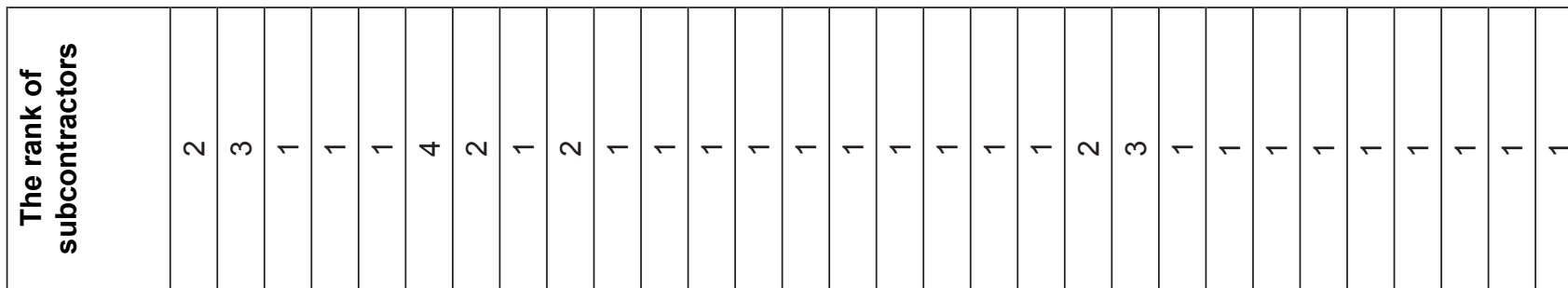

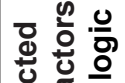

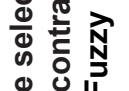

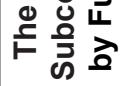

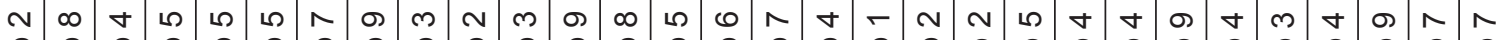

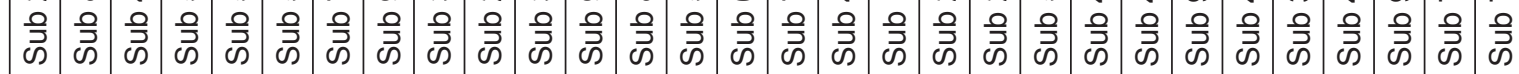

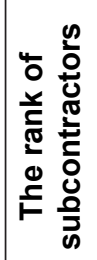

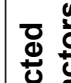

兽总里

-

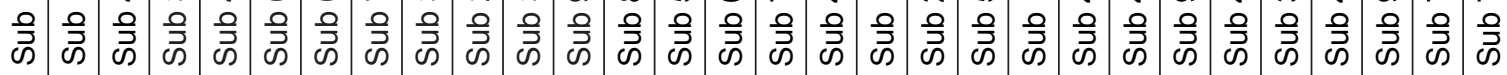

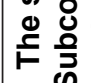

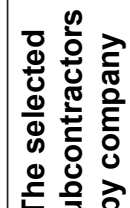

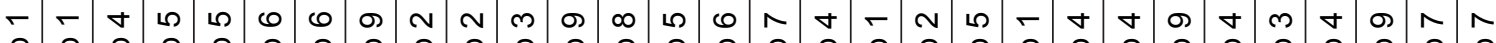

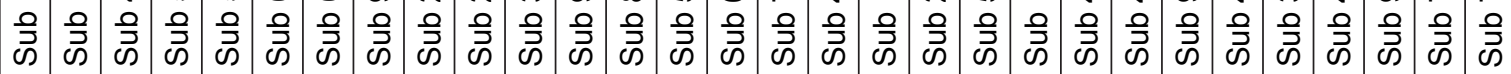

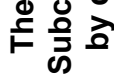

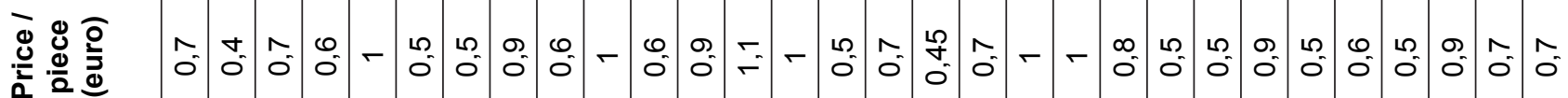

용

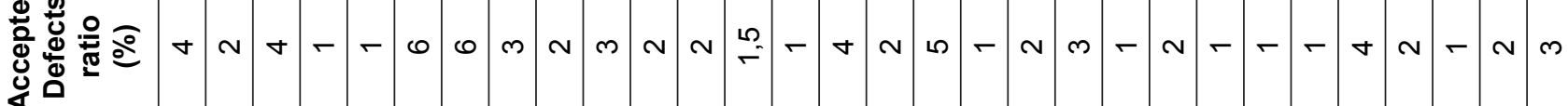

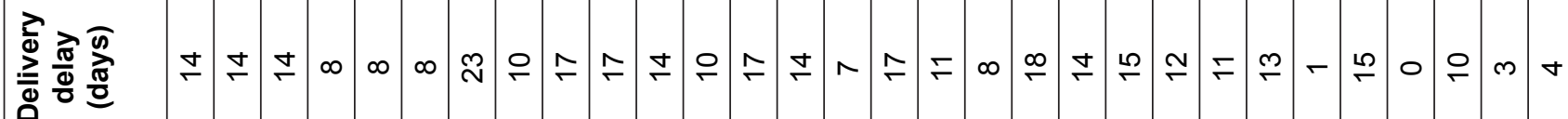

\begin{tabular}{|c|c|c|c|c|c|c|c|c|c|c|c|c|c|c|c|c|c|c|c|c|c|c|c|c|c|c|c|c|}
\hline \multicolumn{2}{|c|}{ 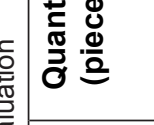 } & 옹 & $\frac{12}{\mp}$ & 훙 & $\frac{0}{6}$ & $\stackrel{\text { O }}{\mathrm{N}}$ & $\frac{m}{m}$ & $\stackrel{\infty}{\stackrel{\infty}{\sim}}$ & $\underset{i n}{\infty}$ & \begin{tabular}{l|l}
10 \\
$\infty$ \\
$\infty$
\end{tabular} & 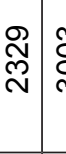 & $\begin{array}{l}\text { ণి } \\
\text { రి }\end{array}$ & 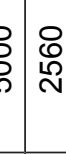 & ○ & 요 & $\begin{array}{l}\stackrel{\mathcal{N}}{N} \\
\text { N }\end{array}$ & 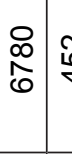 & 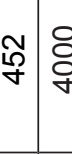 & $\begin{array}{l}0 \\
\infty \\
0\end{array}$ & ৪্ঠি & $\begin{array}{l}\text { ○्र్ల } \\
\text { లెల }\end{array}$ & 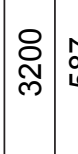 & 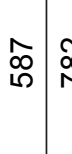 & 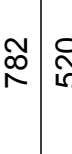 & 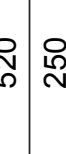 & $\stackrel{\bar{N}}{\stackrel{D}{*}}$ & $\stackrel{\mathbb{N}}{\mathbb{N}}$ & \\
\hline & 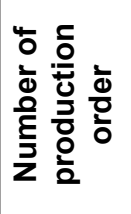 & $\leftarrow$ & $\sim$ & $m$ & $\nabla$ & 10 & 0 & $\Lambda$ & $\infty$ & $\sigma ?$ & 은고 & $\mp \cong$ & $v \stackrel{m}{\sim}$ & $\stackrel{\Xi}{ \pm}$ & $\stackrel{20}{\leftarrow}$ & $\stackrel{\bullet}{1}$ & $\approx g$ & $\stackrel{\infty}{\sim}$ & $\stackrel{\sim}{\sim}$ & $\bar{\sim}$ & $\mathfrak{N}$ & $\stackrel{\sim}{N}$ & $\stackrel{\sim}{\sim}$ & $\stackrel{\sim}{\sim} \mid \stackrel{c}{\overbrace{}}$ & $\stackrel{N}{N}$ & 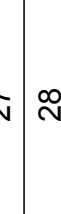 & શ & ભે \\
\hline
\end{tabular}




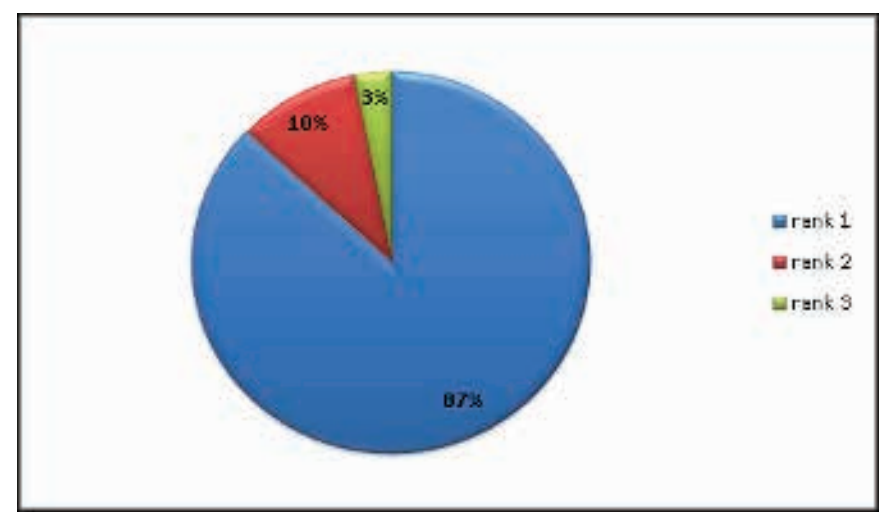

Figure 11: Distribution of the results for the AHP method

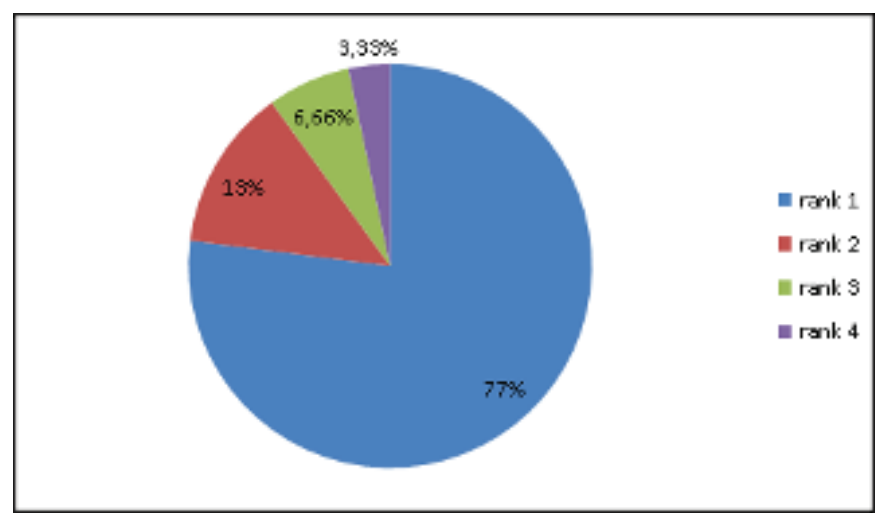

Figure 12: Percentage of coincidence for the fuzzy logic with the choice of the company

From Figure 11, the solutions found in the first rank, second rank, and third rank represent $87 \%, 10 \%$, and $3 \%$, respectively.

From Figure 12, the solutions found in the first rank, second rank, third rank, and fourth rank represent $77 \%, 13 \%, 6.66 \%$, and $3.33 \%$, respectively.

\section{Conclusions}

In this work, we have used two methods for the selection of subcontractors in a Denim manufacturing company. Indeed, the first one was the fuzzy logic and represents a tool to understand practically the similarity, the preferences, and the uncertainty in the inference systems. The second one is the $\mathrm{AHP}$, and it is very important to make a decision or to evaluate several options in situations where no possibility is perfect.

In our case study, it has been proved that the AHP method is more efficient than the fuzzy logic method for the selection of the best subcontractors. Indeed, this interpretation is based on the coincidence percentage between the obtained solutions using the developed models and those corresponding to the best choice made by the managers in the company. Therefore, it can be concluded that the AHP model and the fuzzy logic method are feasible for predicting and selecting subcontractors in the supply chain of our Denim clothing company.

\section{Acknowledgment}

This project is carried out under the MOBIDOC scheme, funded by the EU through the EMORI program and managed by the ANPR.

\section{References}

[1] Chen-Tung, C., Lin, C.-T., Huang, S.-F. (2006). A fuzzy approach for supplier evaluation and selection in supply chain management. International Journal Production Economics, 102, 289-301.

[2] Bayrak, M. Y., Çelebi, N., Taşkin, H. (2007). A fuzzy approach method for supplier selection. Production Planning \& Control, 18, 54-63.

[3] Maurizio, B., Alberto, P. (2010). From traditional purchasing to supplier management: A fuzzy logic based approach to supplier selection. International Journal of Logistics Research and Applications: A Leading Journal of Supply Chain Management, 5(3), 235-255.

[4] Felix, T. S., Kumar, N., Tiwari, M. K., Lau, H. C. W., Choy, K. L. (2008). Global supplier selection: a fuzzy-AHP approach. International Journal of Production Research, 46(14), 3825-3857.

[5] Sharon, M. O. (2009). Development of a supplier selection model using fuzzy logic. Supply Chain Management: An International Journal, 14/4, 314-327.

[6] Devika, K. A. (2013). Integrated fuzzy multi criteria decision making method and multiobjective programming approach for supplier selection and order allocation in a green supply chain. Journal of Cleaner Production, 47, 355-367.

[7] Michat, K. The selection of construction sub contractors using the fuzzy sets theory, Warsaw University of Technology, Faculty of Civil Engineering, Institute of Building Engineering, The Division of Production Engineering and Construction Management, Al. ArmiiLudowej 16, 00-637 Warsaw, Poland.

[8] Min-Yuan, C. (2011). Evaluating subcontractor performance using evolutionary fuzzy hybrid neural network. International Journal of Project Management, 29(3), 349-356.

[9] Okoroh, M. I., Torrance, V. (1999). A model for subcontractor selection in refurbishment projects. Construction Management and Economics, 17, 315-327.

[10] Kumar, M., Vrat, P., Shankar, R. (2004). A fuzzy goal programming approach for vendor selection problem in a supply chain. Computers \& Industrial Engineering, 46(1), 69-85.

[11] Kabbari, M., et al. (2015). Predicting the hydrophobic nature of knitted fabric using fuzzy logic modeling. International Journal of Applied Research on Textile, 3, 58-68.

[12] Mouna, G. et al. (2017). Ann and fuzzy techniques for modeling bagging behaviors of denim fabrics as function of frictional properties. International Journal of Applied Research on Textile, 2, 36-55.

[13] Charles, A. W., John, R. (1993). A multiobjective approach to vendor selection. European Journal of Operational Research, 68(2), 173-184.

[14] William, R. S. (1987). Supplier selection strategies. Journal of Purchasing and Materials Management, 23(2), 7-12. 
[15] Lisa, M. (1990). The supplier selection decision in strategic partenrship. Journal of Purchasing and Materials Management, 26(4), 8-14.

[16] Roodhooft, J., Konings, J. (1997). Vendor selection and evaluation: An activity based costing approach. European Journal of Operational Research, 96, 97-102.

[17] Hinkle, C. L., Robinson, P. J., Green, P. E. (1969). Vendor evaluation using cluster analysis. Journal of Purchasing, 5(3), 49-58.

[18] Zadeh, L. A. (1965). Fuzzy sets. Information and Control, 8(3), 338-353.
[19] Lotfi, B. (1999). Contribution to the control of the asynchronous machine, use of fuzzy logic, neural networks and genetic algorithms. Doctoral thesis, Université de Henri Poincaré, Nancy-l.

[20] Thomas L. S., Kirti, P. (2008). Group decision making: Drawing out and reconciling differences. Pittsburgh, Pennsylvania: RWS Publications.

[21] Saracoglu, B. O. (2013). Selecting industrial investment locations in master plans of countries. European Journal of Industrial Engineering, 4, 416-441. 